\title{
Ecological Urbanism in Latin America
}

\author{
Urbanismo Ecológico na Amética Latina
}

Mohsen Mostafavi, Gareth Doherty

Harvard Graduate School of Design, Cambridge, MA, USA.

It has been nearly six years since Lars Müller Publishers and Harvard University Graduate School of Design (GSD) published the English-language edition of Ecological Urbanism. The book has impacted design education and practice in very palpable ways and has led to numerous publications, programs, and projects. In October 2014, for example, conferences in Chile and Brazil allowed the opportunity to launch Spanish and Portuguese translations of Ecological Urbanism, as well as to present exhibitions of the book and to engage with experts from all over Latin America. The book inspired conversations with remarkable designers, educators, and policymakers from a range of cities and organizations. These interactions led to visits to several impressively built projects including São Paulo's SESC-Pompeia, by Lina Bo Bardi; low-income housing by the firm Elemental; and the Parque Bicentenario in Santiago, by Teodoro Fernández. Building on these events, we are especially happy to have been invited to guest edit this special edition of urbe, with a focus on ecological urbanism in Latin America.

The Ecological Urbanism project at the GSD began as a conference and concurrent exhibition that evolved into the book of the same title. This timely publication of urbe allows us the opportunity to remedy some of the imbalance in the original volume. Some said we focused too much on Western Europe and North America, while not enough on the Global South. Others requested that we provide additional scientific data. Thus, the intent of the upcoming volume is to increase our initial scope and provide additional insight to redress this imbalance on both fronts.

Even in the forthcoming, revised 2016 edition - with translations in Chinese, as well as Spanish and Portuguese, with Arabic and Persian versions available in the near future - a common question still persists: What is ecological urbanism? As stated on the back cover of the first edition of the book: "While climate change, sustainable architecture, and green technologies have become increasingly topical, issues surrounding the sustainability of the city are much less developed." Discussions on sustainability often refer to the very large (global and national implications of climate change) or the very small (at the scale of a building or even more diminutive objects). Moreover, not a lot of literature deals with the sustainability of the city itself. Even fewer studies have examined the landscapes in between, with the intent to determine whether they should be urban or rural. Of course, individual cities range in size, but collectively they are often ignored in discussions on

MM is the Dean and Professor at the Harvard Graduate School of Design, e-mail: mohsen_mostafavi@gsd.harvard.edu GD is Assistant Professor at the Harvard Graduate School of Design, e-mail: gdoherty@gsd.harvard.edu 
sustainability. When addressing issues of sustainability, it is becoming increasingly more requisite that new approaches toward urbanism and planning consider cities as entities in their own right - this is where ecological urbanism takes form.

While there are numerous theoretical arguments for what cities are, what constitutes an urban environment, and indeed what urbanism means in general, the common fact remains - a lot of people live in cities. Urban areas typically yield higher concentrations of the global population. Yet somehow the city has too often been neglected in discussions on ecology and the environment. Rather than viewing urban settings negatively, as some environmentalists are prone to do, we suggest accepting urbanism as a fact of life that should be embraced and enjoyed. Our objective is to work with the city and strive to better understand the complex urban fabric that binds together so many systems.

Having touched on the urban, we now refer to ecology. As the book's description divulges, "The premise of this project is that an ecological approach is urgently needed." (Mostafavi and Doherty, 2010, book cover). Here, the use of the word "ecology" is intended to include social and aesthetic dimensions, as well as environmental. This more encompassing view of ecology is not new. It's had a long trajectory, with many historic examples in Latin America and elsewhere. Writing some thirty years ago, the French philosopher and social scientist, Félix Guattari (2000), called for three ecological registers of environmental, social, and "the mental" or human subjectivity:

[...] Despite having recently initiated a partial realization of the most obvious dangers that threaten the natural environment of our societies, they are generally content to simply tackle industrial pollution ... from a purely technocratic perspective, whereas only an ethico-political articulation - which I call ecosophy - between the three ecological registers (the environment, social relations, and human subjectivity) would be likely to clarify these questions.

The imagination of sustainable cities requires a view of ecology that goes beyond environmental concerns and embraces social and aesthetic ecologies as well. One wonders if these three ecologies are still as inclusive, or if we need to consider additional ecologies to deliver a more encompassing methodology. To that end, Ecological Urbanism addresses each of Guattari's points and more.

This ecological approach is further described "[...] as an imaginative and practical method for addressing existing as well as new cities." (Mostafavi and Doherty, 2010, book cover). This projective and speculative component of ecological urbanism is critical to the future success of sustainable design. Too often, environmental design is presented as a problem-solving agenda with moral/ethical ramifications, or with preconceived aesthetics that identify it as sustainable. But ecological urbanism should not lose track of the creativity that speculative - yet practical - imaginations provide. We should also point out that ecological urbanism is not just about design of new cities of the future, or so-called "eco-cities." It is more importantly understood as the design, adaptation and retrofitting of all cities.

"Ecological Urbanism considers the city with multiple instruments and with a worldview that is fluid in scale and disciplinary focus." (Mostafavi and Doherty, 2010, book cover). Here, the emphasis is on the multi-scalar dimension of ecological urbanism, which operates from the very small to the very large scales. An example of this range could include the Little Sun, a palm-sized solar-powered torch/lamp designed by Olafur Eliasson; cloud catchers that enable water collection in the Atacama Desert, designed by a team at Pontificia Universidad Católica de Chile; and a biomass cogeneration plant designed by BIG, which combines a power plant with a greenhouse to create a new form of public space. Operating simultaneously at various scales, ecology and urbanism are reconciled through the act of design. "Design provides the synthetic key to connect ecology with an urbanism that is not in contradiction with its environment." (Mostafavi and Doherty, 2010, book cover).

The symbiotic relationship between densely built environments and the ecologies that share their space must be cultivated in ways that acknowledge that urban systems are not going away. The city will not be replaced with green pastures and so it needs to be accepted and seen for all its cultural, social, and artistic benefits. Ecological Urbanism modestly ends with the following declaration: "The promise is nothing short of a new ethics and aesthetics of the urban." (Mostafavi and Doherty, 2010, book cover). In this regard, aesthetics and ethics are intertwined. 


\section{Toward a Latin American Ecological Urbanism}

Latin American cities provide a fertile context for developing case studies. There are sets of multi-scale urban projects that will resonate with ecological urbanism agendas and inform future interventions across the built and natural environments. Consequently, this special edition is not only intended to extend the body of work associated with Latin American ecological urbanism, but this initiative also offers an opportunity to learn from the multitude of projects already underway. Hopefully it can help to initiate long-term collaborations for developing case studies, projects, and research that facilitates both academic material and policy recommendations.

While we compiled the information for Ecological Urbanism, it emerged that the work of many visionary practitioners cannot be easily classified into merely one discipline. Their work transcended the traditional categorizations of landscape architect, architect, urban designer, or planner. Therefore, we strived to find ways to avoid prejudicing any one discipline over another. In doing so, ten words emerged from the texts and projects that serve to explain the practical applications of the ideas in the book - anticipate, sense, curate, collaborate, produce, interact, mobilize, measure, adapt, and incubate. These words, all verbs, are a way of thinking about ecological urbanism and are briefly described below.

\section{Anticipate}

The act of catching a ball implies a form of anticipation - you know it's coming but don't know exactly where it will land. So, you have to position yourself in anticipation of the various possibilities. The texts in this section of Ecological Urbanism anticipate cities of the present and the future and, as Rem Koolhaas suggests, in looking forward, we also need to look back. Or, as Homi K. Bhabha tells us, "It is always too early or too late to talk of the 'cities of the future."' (Mostafavi and Doherty, 2010, book cover). We need to reflect on the unbuilt. Or simply put, what did not happen for one reason or another.

\section{Sense}

If we are to design the city in a more ecological way - embracing multiple ecologies - then we need to know the city better. It is in sensing the urban ecologies that we can design with them in more nuanced and effective ways. There are two types of sensing discussed in this section. One is related to how technologies might be utilized to understand the city in a more subtle way, and the other caters to the human senses of touch, sight, and smell.

\section{Curate}

To curate at the urban scale implies an active and simultaneous engagement with design as well as with the management of the various ecologies environmental, social, and political. Herbert Dreiseitl's project on new waterscapes in Singapore, offers an innovative plan for curating the city's water resources. His firm, Atelier Dreiseitl, combines traditional water management strategies with recreational uses and ecological programs, turning wastewater into an asset.

\section{Collaborate}

Although it seems obvious that we need to work outside professional and disciplinary structures, it is not so easy to do. Collaborative efforts are often hampered by divergences of language and terminology, never mind ways of thinking and working. This series of short texts by professors from across various departments and schools at Harvard University highlights not just the similarities in approaches to ecology, but also the differences. The collaboration sections appear three times in the book, partly to reinforce the point that to collaborate is an essential aspect of ecological urbanism.

\section{Produce}

Cities consume resources. That is not in question. What is in question is whether or not they can ever produce more than what they consume. Will they be able to provide an abundance of energy and food as well as money and wealth? For instance, half the world's population lives in cities, yet over three-quarters of the world's energy is consumed by cities. If cities are ever to become more productive, then it is imperative to move beyond the idea that energy production and all its ancillary industries are something that happens far away. 


\section{Interact}

Ecology, as the "study of the interactions of organisms and the environment," is based on the principle of interaction. In his maps of urban regions, Richard T.T. Forman investigates the interaction between cities and their hinterlands. Forman charts 38 urban regions; areas of 1,000 square kilometers or more, including Tehran, demonstrating in the process that you cannot understand a city merely by its physical limits, as cities interact with their regions and extend well beyond.

\section{Mobilize}

To mobilize might relate to rallying in pursuit of a social aim, but it might also relate to mobility. As Richard Sommer tells us in his text, "Mobility, Infrastructure, and Society," these are not mutually incompatible aspects of the city - mobility and social justice are intertwined. Answering questions of mobility is paramount to thinking of more ecological cities.

\section{Measure}

The metrics with which we measure ecological cities are fundamentally important for how we design them. Stefano Boeri outlines five challenges for large-scale urban policies that propose new ideas that link urban ecology with economic development. Ecological urbanism should create new hybrids, overcome disciplinary boundaries, and balance established binaries between the environment and economics; technology and the human; the rational and the irrational; and, as Kathryn Moore suggests, nature and culture.

\section{Adapt}

Adaptation is a trait that refers to both a current state of being and the process by which an organism responds to changing conditions in order to maintain fitness, or efficiency. Nina-Marie Lister equates adaptive design with sustainable design. She tells us "[...] resilient, adaptive, and thus sustainable design means 'thriving,' and therefore must necessarily include economic and ecological health and cultural vitality as planning and design goals." (Mostafavi and Doherty, 2010, book cover).

\section{Incubate}

When we think of incubation we might think of a bird sitting on a nest of eggs in order to hatch them, or of the care of newly hatched chicks. Incubating implies the idea of nurturing care over a period of time, both before and after birth. Urban ecologies need to be nurtured, cared for, and fostered over time. Incubation is an essential component of ecological urbanism.

While these verbs provide a framing for ecological urbanism, they are not definitive. Some verbs are more applicable in different contexts. If we are to practice in a more ecological way - where ecology is understood in this broad sense - then we need to augment our understanding to consider the various social, political, and aesthetic ecologies. One aim of this special volume has been to include diverse perspectives from a host of countries to the rich and fruitful contributions on ecological urbanism. This volume contains a diversity of perspectives and topics relating to public health, participatory methods, and new forms of urban development.

"How Can Ecological Urbanism Promote Human Health?" Fajersztajn et al., from the Faculty of Medicine in the Universidade de São Paulo, put forward the argument that ecological urbanism can make a real contribution to public health, and consequently, the health of cities. This goal of healthier cities may be enabled through the approach of ecological urbanism, which is "fluid in scale and disciplinary approach." In this case, urban designers can be considered the doctors of the city.

Gonzalo Salazar and Daniela Jalabert, authors of "Towards a Landscape Ecosophy" discuss the epistemological and ethical foundations of ecological urbanism. They suggest a concept of "landscape ecosophy" to help balance the surprising disconnection that can occur between urban residents and their immediate hinterland. Based on their fieldwork in the Villarrica-Pucón urban system in the Araucanía region of Chile, they tell us that it is "the manner we perceive the relationship between the city and its natural ecosystem, [that] informs and significantly 
determines the very praxis of urbanterritorial planning." These types of perceptual ecologies are critical for ecological urbanism.

In "Rehabitar la montaña," Claghorn, et al., in collaboration with Leibniz University Hannover and EAFIT University, write about the anticipation and mitigation of risk in the mountainous periphery of the city of Medellín, Colombia. The authors propose five pilot projects to test risk mitigation strategies: 1) monitoring and early warning systems; 2) drainage improvements; 3) urban agriculture; 4) slope forestation; and 5) developing sites with supplied services.

In "Urbanism and Ecology in Buenos Aires," Leonardo Fernández, from the Universidad Nacional de General Sarmiento, traces some of the historic influences on the urban form of Buenos Aires and provides an overview of the processes of urbanization within its regional landscape. Fernández states that the concept of ecological urbanism is situated in Buenos Aires through the main implications of the current phase of urbanization.

Louise Barbalho Pontes and Ana Cláudia Duarte Cardoso, from the Universidade Federal do Pará (UFPA) in Belém, discuss the potentials for new forms of urbanization presented in Amazonia, and the opportunity to "reconcile urbanism and ecology." In "Open Spaces: Windows for Ecological Urbanism in The Western Amazon," the authors make the case for deconstructing the dichotomy between city and nature, providing the example of the city of Marabá in Western Amazonia.

In their essay, "Challenges of the Urban Peripheral Landscapes," Catharina Pinheiro Cordeiro dos Santos
Lima and Caio Boucinhas ask how to change not just the landscape itself but also perceptions, reframing the urban periphery as a positive place in which to live. The article raises the issue of participatory methods, which can allow designers to engage with the multiple ecologies, as in the case of the Pinheirinho d'Água Park in São Paulo. The essay raises the issue of landscape as an important aspect of ecological urbanism. The authors tell us, "If planned collectively, it can help in the creation of revolutionary processes that lead to the players involved becoming the subjects of their own story."

The above peer-reviewed essays present distinct ways of thinking about ecological urbanism within a Latin American context, where design can be a response to the building of relationships between the various components of a given place. Ecological urbanism does not seek to privilege any one approach over another, but is instead inclusive, malleable, and able to adjust to various scales, situations, and societies. We hope that this volume will inspire further conversations, and diverse points of view, on ecological urbanism in Latin America.

\section{References}

Guattari, F. (2000). The three ecologies (Translated by Ian Pindar and Paul Sutton, p. 27-28). London: The Athlone Press.

Mostafavi, M., \& Doherty, G. (2010). Ecological urbanism. Frankfurt: Lars Müller. 


\section{Errata}

In the article "Ecological Urbanism in Latin America", DOI number: 10.1590/2175-3369.008.001.SE07, published in urbe - Brazilian Journal of Urban Management, 8(1): 7-11, on page 7:

Where it reads:

"Urbanismo Ecológico na Amética Latina"

It should read:

"Urbanismo Ecológico na América Latina"

In the same article, on page 11:

Where it reads:

“Mostafavi, M., \& Doherty, G. (2010). Ecological Urbanism. Frankfurt: Lars Müller."

It should read:

"Mostafavi, M., \& Doherty, G. (2010). Ecological Urbanism. Zurich: Lars Müller." 